\title{
Experimental and Numerical Study of Ceiling Jet Fire in a Confined Reduced-Scale Corridor
}

\author{
SONGYANG LI ${ }^{1}$, ZHENGHUA YAN ${ }^{2}$, RUOWEN ZONG ${ }^{1}$, BENGT SUNDÉN ${ }^{2}$, and GUANGXUAN \\ $\mathrm{LIAO}^{1}$ \\ ${ }^{1}$ State Key Laboratory of Fire Science \\ University of Science and Technology of China \\ Hefei, Anhui 230026, PR China \\ ${ }^{2}$ Department of Energy Sciences \\ Lund University \\ Lund, 22100, Sweden
}

\begin{abstract}
Safety evaluation and assessment becomes an important topic in the design and operation of tunnels and other underground corridors nowadays. The computational fluid dynamics (CFD) model is an indispensable tool in this process, which can predict the possible fire scenarios by calculating the temperature, concentration, velocity and heat transfer in the domain of concern. In this paper, a validation study for a newly developed CFD code SIMTEC is presented, and the modeling results are compared with experimental data which were obtained through a batch of fire tests in a reduced-scale corridor. The simulations agree reasonably well with measured results. In general, the CFD model predicts the hot layer temperature and $\mathrm{CO}_{2}$ concentration with good accuracy, especially at the position closer to the end of the corridor. The $\mathrm{CO}$ concentration close to the fire source is also well captured in the simulation. However, the $\mathrm{CO}$ concentration prediction downstream, far away from fire source, is poor. In this study, the effect of corridor fire intensity was also investigated, by varying the fire source size while with other parameters fixed. Both the measurements and the simulation indicate that the average hot layer temperature near the fire source did not change obviously despite the increase in the fire source size.
\end{abstract}

KEYWORDS: tunnel, ceiling jet, corridor fires, reduced-scale model, CFD.

\section{INTRODUCTION}

In China, during the first ten years of the 21st century, hundreds of tunnels and other underground spaces have been constructed. With this, fire safety issues have to be seriously considered. Recently, there has also been much concern in the developed countries about the fire safety of road and rail tunnels. In tunnels or other underground corridors, the combustion products of fire are forced to transfer in one or two directions, resulting in a very fast smoke movement. Besides, it is difficult to exhaust the smoke and heat. These may lead to a rapid threat to life. For this, it is necessary to have a deep understanding of the behavior of fire and smoke movement in a tunnel.

Research work in the study of tunnel and long corridor fires is mainly focused in two areas: (1) fire experiments in small scale and sometimes in full-scale tunnels, investigating the propagation of fire plume and smoke movement, and typically aimed at studying the critical velocity for longitudinal ventilation system in tunnels; (2) theoretical simulations of tunnel and corridor fires based on zone modeling and field modeling techniques. A series of fire tests was conducted by Xue on a small-scale tunnel, which was $6 \mathrm{~m}$ long and with rectangular cross section $0.3 \mathrm{~m}$ high and $0.9 \mathrm{~m}$ wide [1]. Ventilation velocity, heat release rate and temperature distributions are measured under quasi-steady conditions, and flow patterns under different ventilation velocities were analyzed and discussed. In the last 20 years, some full-scale tunnel fire tests have been carried out. The full-scale tunnel fire tests of the EUREKA EU-499 project were conducted in the Repparfjord tunnel, with the smoke temperature and HRR of fire analyzed and discussed [2].The Runehamar fire tests carried out in 2003, as a collaboration project between SP and the European UPTUN project, also revealed the information of HRR and the temperature of hot smoke under the ceiling $[3,4]$. Several similar tests, including the Byfjord and Bømlafjord tunnel fire tests in 1998 and 1999, Ømbesvik tunnel tests over the years 1997-2001, and Hanekleiv and Banehei tunnel tests in 2000 and 2001, have been conducted [5]. Zone models have been developed over the years, even before the widespread application of computers in fire research area. The most popular zone model is CFAST [6], developed by NIST, aiming to model the smoke movement in compartmented structures. A three-layer zone model, Fire growth And 
Smoke movement In Tunnel (FASIT) [7], was developed by Charters to simulate fire growth movement in tunnels. As for field models, some are general purpose codes, such as Fluent, CFX, PHOENICS and STAR-CD, and applicable to variety of problems, while some others are specially developed for fire related problems, like FDS [8] and JASMINE. Jain et al. made a comparative study of CFAST and CFX predictions through analyzing the temperature and velocity profiles generated by a tunnel fire [9]. Cox and Kumar first applied the JASMINE code to road tunnel fire problems [10]. Tuovinen also adopted JASMINE to calculate the fire plume under the ceiling of a large corridor [11]. Lee used FDS to analyze the effect of the aspect ratio on smoke movement in tunnel fires [12]. Hu also validated the application of FDS through a series of full-scale fire tests conducted in two vehicular tunnels of lengths 3.27 and $1.032 \mathrm{~km}[13]$.

Generally, small-scale experiments alone are not enough to reproduce full-scale fire characteristics, although they may provide useful information. More sufficient investigation and research can be carried out by full-scale experiments but they are costly and expensive. Therefore, numerical simulation provides a possible solution to this dilemma. Nevertheless, numerical codes should be validated by full- or reducedscale fire tests to support practical application.

In this work, a series of fire experiments were conducted to study the fire in a reduced-scale corridor. Corresponding CFD simulations were performed using CFD software package SIMTEC (Simulation of Thermal Engineering Complex) v5.1.0 [14] which is developed by one of the authors, Yan. The simulation was validated against the experimental measurements. The results, including ceiling jet temperature, concentration of $\mathrm{CO}$ and $\mathrm{CO}_{2}$, are compared and analyzed. Furthermore, the effects of fire source size on the temperature and gas concentration profile of the ceiling jet fire are investigated and discussed.

\section{EXPERIMENTAL PROCEDURE}

The experimental tests were conducted in a reduced-scale corridor model, which was $5 \mathrm{~m}$ long with square cross section $0.5 \mathrm{~m}$ wide, at University of Science and Technology of China, Hefei. This model was basically scaled from a real-life underground shopping street, aiming to study the fire properties and the smoke movement in such a confined long space, as well as to validate the CFD code SIMTEC [14]. The schematic view of the experimental layout and the corridor is shown in Fig. 1. Figure 1a is a longitudinal section from rear side view, and Fig. $1 \mathrm{~b}$ is a cross-section from right end view. Objects that are not in the plane are shown as thin dashed lines. There was a retractable opening of size $0.5 \times 0.5 \mathrm{~m}^{2}$ at each end. One was fully opened during each experiment, and the other, which was near the fire source, was closed immediately after the ignition. The material forming the outside of the whole corridor was steel of $4 \mathrm{~mm}$ thickness. The sidewalls, ceiling and floor were made of aluminum silicate board of $30 \mathrm{~mm}$ thick, which can withstand high temperature up to $1100{ }^{\circ} \mathrm{C}$ and insulate heat leakage from outside. Three windows of $30 \times 50 \mathrm{~cm}^{2}$, made of fire-proof glass, were set up in one side of the wall for the convenience of observation. N-heptane pool fires were placed in one end of the corridor in every test.

Three types of data were measured in all six tests, including gas temperature, mass of fire source and gas concentrations for $\mathrm{CO}, \mathrm{O}_{2}$ and $\mathrm{CO}_{2}$. An electronic balance (Sartorius, LA64001S) was fixed below the corridor model to measure the mass loss rates of the fire source through a support plate. Fifteen thermocouples (K-Type, $\phi=1 \mathrm{~mm}$ ) were set to measure the temperatures at different sections and different heights in the corridor, where there were five sections in the longitudinal direction $(0.5 \mathrm{~m}, 1.5 \mathrm{~m}, 2.5 \mathrm{~m}$, $3.5 \mathrm{~m}, 4.5 \mathrm{~m}$ away from one end) and three points in the vertical direction of each section $(12.5 \mathrm{~cm}, 25 \mathrm{~cm}$, $37.5 \mathrm{~cm}$ below the ceiling). The output data of thermocouples was collected through a data transmission module, along with the balance signal. The number of each thermocouple is illustrated in Fig. 1a. A KANE KM9106 smoke composition analyzer was utilized to measure gas concentration in the smoke layer of the corridor, where the probe was inserted through one hole out of points 4, 7, 10, and 13 in different tests. Since there is only one gas probe available, four parallel tests with same fire configuration (from No. 1.a to 1.d, as shown in Table 1) were conducted in this work, in order to measure gas concentration at different distances from the fire. Due to some technical problems, the Tests measurements in tests 1.c and 1.d failed. As a result, the gas concentration measurement data from Tests 1.c and 1.d cannot be used here.

The detailed set-up of each test is shown in Table 1. The fuel thickness was set to make sure that fire could burn long enough for the occurrence of fully developed fire. All data were measured every second right after the trays were ignited until the extinguishment of the fire. 


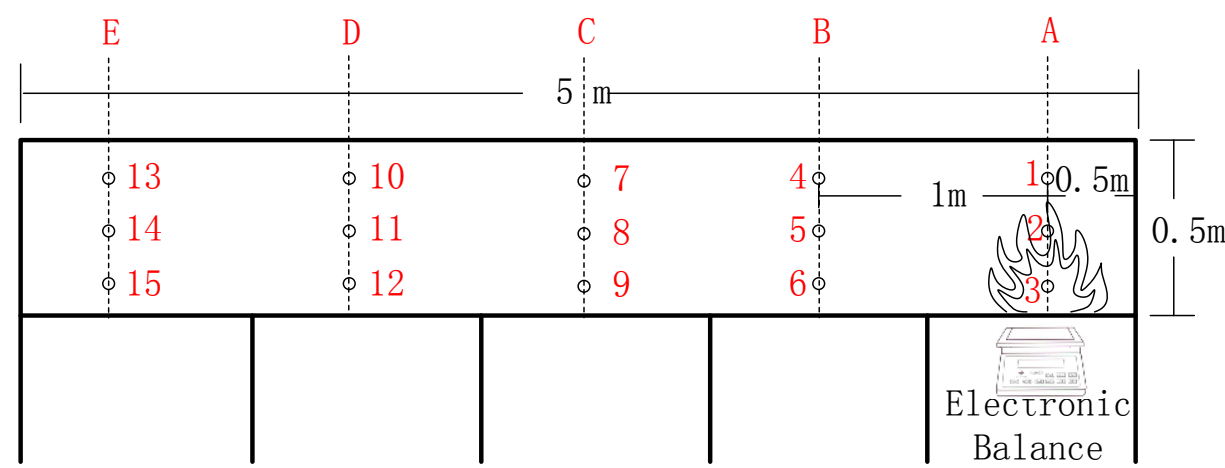

(a)

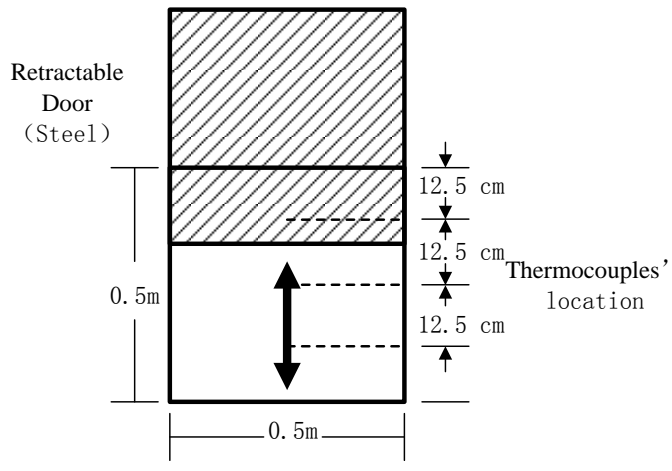

(b)

Fig. 1. Geometry of the experimental set-up: (a) longitudinal section view; (b) cross-section view.

Table 1. The description of experimental Tests (1.c and 1.d failed due to some technical problems).

\begin{tabular}{|c|c|c|c|}
\hline Test number & $\begin{array}{c}\text { Fuel dimension } \\
(\mathbf{c m} \times \mathbf{~ c m})\end{array}$ & $\begin{array}{c}\text { Fuel } \\
\text { weight }(\mathbf{g})\end{array}$ & $\begin{array}{c}\text { Gas probe } \\
\text { location }\end{array}$ \\
\hline $1 . \mathrm{a}$ & $17 \times 17$ & 630 & Section B beside TC 4 \\
\hline $1 . \mathrm{b}$ & $17 \times 17$ & 632 & Section C beside TC 7 \\
\hline $1 . \mathrm{c}$ & $17 \times 17$ & 635 & Section D beside TC 10 \\
\hline $1 . \mathrm{d}$ & $17 \times 17$ & 637 & Section E beside TC 13 \\
\hline 2 & $20 \times 20$ & 723 & Section B beside TC 4 \\
\hline 3 & $15 \times 15$ & 497 & Section B beside TC 4 \\
\hline
\end{tabular}

\section{CFD MODELING OF THE FIRE TESTS}

The turbulent flow and combustion in a fire is governed by the conservation of mass, momentum and energy. In order to simulate the fire processes, one needs to solve the governing equations numerically, together with consideration of turbulent combustion, convective heat transfer, thermal radiation and soot formation, etc.

\section{Governing Equations}

All experimental tests in this present work were simulated by using the advanced fire simulation software package SIMTEC [14]. This software is fully parallelized. It has pre-processor, post-processor and a variety of different advanced models for representing turbulent combustion, thermal radiation, turbulence and conjugate heat transfer, etc. It supports both LES (large eddy simulation) and RANS (Reynolds averaged Navier-Stokes) simulations. In this study, the LES approach is adopted. For LES, the filtering equations are involved in accordance with the cell size of the computational domain. In the practical sense, physical 
processes occurring on scales larger than the size of a cell are calculated directly, and those on the sub-grid scale (SGS) are modeled or approximated. Together with the sub-models, a set of density weighted spatially filtered conservation equations, comprising continuity, momentum, energy and species equations were numerically solved [15]:

Continuity equation:

$$
\frac{\partial \rho}{\partial t}+\frac{\partial\left(\bar{\rho} \tilde{u}_{i}\right)}{\partial x_{i}}=0
$$

Momentum equation:

$$
\begin{aligned}
& \frac{\partial\left(\bar{\rho} \tilde{u}_{i}\right)}{\partial t}+\frac{\partial\left(\bar{\rho} \tilde{u}_{i} \tilde{u}_{j}\right)}{\partial x_{j}}=-\frac{\partial \bar{p}}{\partial x_{i}}+\frac{\partial}{\partial x_{j}}\left[\mu\left(\frac{\partial \tilde{u}_{i}}{\partial x_{j}}+\frac{\partial \tilde{u}_{j}}{\partial x_{i}}\right)-\frac{2}{3} \mu \delta_{i j} \frac{\partial \tilde{u}_{k}}{\partial x_{k}}+\tau_{i j}\right]+\bar{\rho} a_{g i} \\
& =-\frac{\partial \bar{p}}{\partial x_{i}}+\frac{\partial}{\partial x_{j}}\left[\mu\left(\frac{\partial \tilde{u}_{i}}{\partial x_{j}}+\frac{\partial \tilde{u}_{j}}{\partial x_{i}}\right)-\frac{2}{3} \mu \delta_{i j} \frac{\partial \tilde{u}_{k}}{\partial x_{k}}+\tau_{i j}\right]+\left(\bar{\rho}-\rho_{\infty}\right) a_{g i}
\end{aligned}
$$

Energy equation:

$$
\frac{\partial(\bar{\rho} \tilde{h})}{\partial t}+\frac{\partial\left(\bar{\rho} \tilde{u}_{j} \tilde{h}\right)}{\partial x_{j}}=\frac{\partial}{\partial x_{j}}\left(\frac{\mu}{\operatorname{Pr}} \frac{\partial \tilde{h}}{\partial x_{j}}+q_{j, h}\right)+\bar{S}_{h}
$$

Species equation:

$$
\frac{\partial\left(\bar{\rho} \tilde{Y}_{i}\right)}{\partial t}+\frac{\partial\left(\bar{\rho} \tilde{u}_{j} \tilde{Y}_{i}\right)}{\partial x_{j}}=\frac{\partial}{\partial x_{j}}\left(\frac{\mu}{S c} \frac{\partial \tilde{Y}_{i}}{\partial x_{j}}+q_{j, Y_{i}}\right)+\bar{R}_{i}
$$

where the over bar $(-)$ and the tilde $(\sim)$ represent spatial filtering and Favre spatial filtering, respectively. In the above equations, the filtered enthalpy source term $\bar{S}_{h}$, filtered reaction rate $\bar{R}_{i}$, the sub-grid scale (SGS) stress $\tau_{i j}$ and the SGS scalar fluxes including $q_{j, h}$ and $q_{j, Y_{i}}$ need to be modeled.

Turbulence and turbulent combustion sub-grid scale models overcome the closure difficulty resulting from filtering the partial differential equations. SIMTEC provides a variety of sub-models with different accuracies and reliabilities for modeling the relevant fire process. In this study, for simplicity and reducing computational time, relatively simple sub-models were adopted. The sub-models used in the simulations are listed in Table 2. Among these applied sub-models, it is worth to mention that the used SGS turbulent combustion model is a modified model based on the eddy dissipation concept (EDC). The EDC model was proposed by Magnussen [16] for RANS computation. With a proper replacement of time scale estimation, it can easily be extended for LES computation [15]. However, in this original form of the EDC model, fast chemistry is assumed. This assumption may well not be valid at the under-ventilated combustion condition, where large amounts of $\mathrm{CO}$ can be produced and the reaction is slowed down and partially locally extinguished. In this case, for a reasonable simulation of the turbulent combustion, the fast chemistry assumption needs to be abandoned and careful consideration of chemical kinetics is necessary. A new turbulent combustion model with consideration of chemical kinetics has now been developed and implemented in SIMTEC. However, with consideration of kinetics, the computation will be substantially heavier. As a result, due to computer resource limitations and for simplicity, it was not used in this study. It is to be used in a future complementary study. Since the fires studied here are with under-ventilation conditions, particularly at the later stages, to make an approximate consideration of the slow chemistry and 
local extinguishment without applying the chemical kinetics, in this study, the EDC model was modified to allow local flame to extinguish. In the studied fire, premixed flame, partially premixed flame and nonpremixed flame can locally exist. The modification empirically accounts for the local extinguishment of the premixed, partially premixed and non-premixed flames. Because of the space limit, this modification cannot be fully presented here. The details of this modification can be found in [14].

Table 2. List of sub-models chosen in the fire scenario modeling.

\begin{tabular}{|l|l|}
\hline Turbulence model & Smagorinsky model [17] \\
\hline Radiation property model & Modak's model [18] \\
\hline Convective heat transfer & Non-isothermal wall function \\
\hline Heat transfer model in solid & Numerical solution using a separate set of solid grid system [19] \\
\hline & A modified eddy dissipation concept (EDC) for turbulent \\
& combustion, with 4 steps global reactions \\
& $\mathrm{C}_{7} \mathrm{H}_{16}+3.5 \mathrm{O}_{2}=7 \mathrm{CO}+8 \mathrm{H}_{2}+0.05$ Soot \\
Combustion model & $\mathrm{C}_{7} \mathrm{H}_{6}+7 \mathrm{H}_{2} \mathrm{O}=7 \mathrm{CO}+15 \mathrm{H}_{2}+0.05 \mathrm{Soot}$ \\
& $\mathrm{H}_{2}+0.5 \mathrm{O}_{2}=\mathrm{H}_{2} \mathrm{O}$ \\
& $\mathrm{CO}+\mathrm{H}_{2} \mathrm{O}=\mathrm{CO}_{2}+\mathrm{H}_{2}$ \\
\hline
\end{tabular}

\section{Numerical Method}

In SIMTEC, a series of effective numerical schemes are adopted. The filtered governing equations were discretized using the finite volume method. A second order TVD (total variation diminishing) scheme was applied to approximate the variables at the cell faces in the finite volume discrete equations. The diffusion term was computed based on the central differencing scheme. On the time coordinate, all the computations were explicitly time marched, with the momentum equations solved based on a second order fractional-step Adams-Bashford scheme and the transport scalars computed using a second order Runge-Kutta method. The Poisson equation for pressure from the continuity equation was solved using a parallel solver.

The time step for the time integration was chosen with reference to the CFL condition and viscous stability requirement for the resolved scales. In this study, typical time step is about $1.0 \mathrm{~ms}$.

\section{Set-Up of the Simulations}

In the simulation, model parameters were set to correspond to the ones in the experiments, such as geometric configuration of the corridor, opening size, fire location and wall material, etc.

Two grid resolutions of calculation domain was adopted, where the coarse one was 65,100 non-uniform gas cells with 62, 30 and 35 nodes in the $\mathrm{x}, \mathrm{y}$, and $\mathrm{z}$ directions, respectively, and the fine one was 160,650 nonuniform gas cells with 102, 45 and 35 nodes in the $\mathrm{x}, \mathrm{y}$, and $\mathrm{z}$ directions. Because hot gas impinged and flowed under the ceiling, where turbulence, strong gradients, and heat transfer to walls is expected, a very fine division of the y direction was used at the upper layer of the corridor in order to compute these effects with reasonable accuracy. The smallest y intervals were only $1 \mathrm{~cm}$ in the coarse resolution and $0.5 \mathrm{~cm}$ in the fine resolution. Furthermore, the mesh near the fire source was finer, with node distances of $1-2 \mathrm{~cm}$, than it was far away from sources, where node distances of 10-20 cm were applied. The non-uniform fine grid is shown in Fig. 2, with clustering applied to the fire source and the ceiling layer to provide an optimum resolution. For clarity, the scale of Fig. 2a is enlarged in the Y direction.

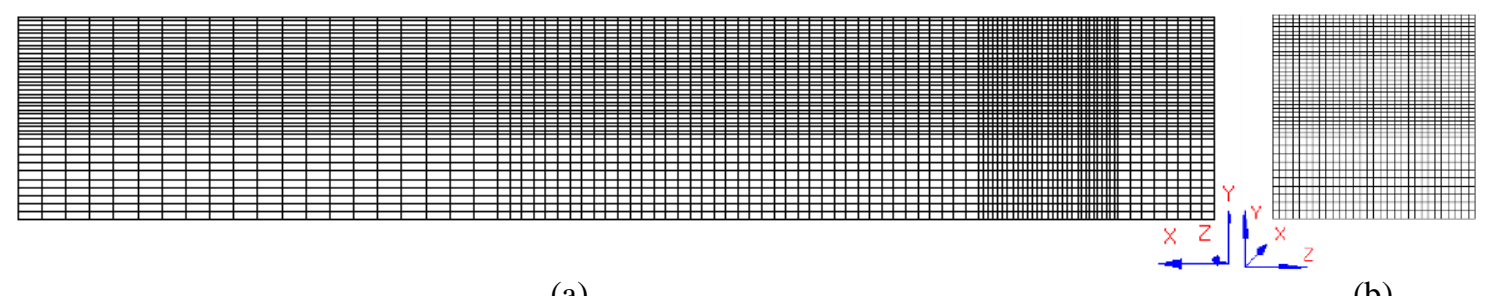

(a)

(b)

Fig. 2. The fine resolution mesh: (a) longitudinal section view; (b) cross-section view. 
The heat release rate (HRR) of the fire source, which is thought of as the 'driving force' behind the fire plume and the ceiling flow, was input into SIMTEC by referring to the measured HRR in each test. The HRR curves of the experiments are illustrated in Fig. 3. From the HRR input, SIMTEC automatically calculated the rate of fuel flow, which is discharged from a simulated burner at the floor level.

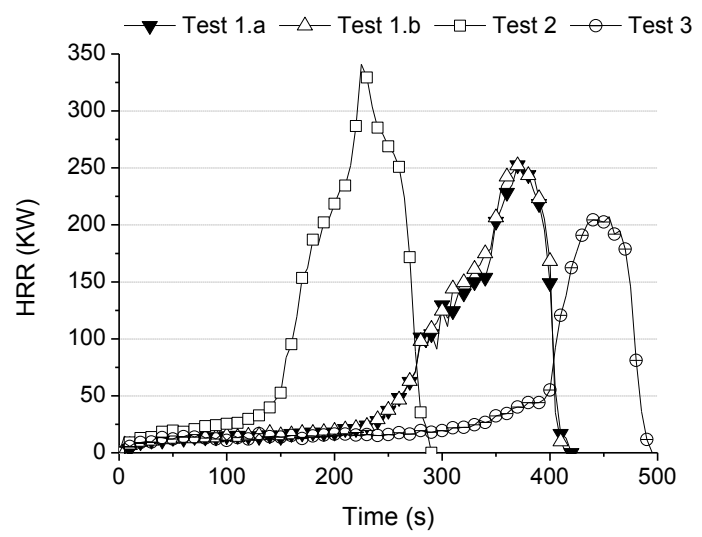

Fig. 3. The heat release rate of fire source for SIMTEC input.

The environment temperature was set as $15{ }^{\circ} \mathrm{C}$ in each scenario. The physical parameters for wall materials of the modelled corridor were taken from the testing report of the product company: density $150 \mathrm{~kg} / \mathrm{m}^{3}$, specific heat capacity $960 \mathrm{~kJ} / \mathrm{kg} \cdot \mathrm{K}$, thermal conductivity between $0.035 \mathrm{~W} / \mathrm{m} \cdot \mathrm{K}\left(20{ }^{\circ} \mathrm{C}\right)$ and $0.15 \mathrm{~W} / \mathrm{m} \cdot \mathrm{K}$ $\left(1200{ }^{\circ} \mathrm{C}\right)$ with an approximately linear growth against temperature. In SIMTEC, an additional grid system is implemented for calculating the important heat transfer inside the solid phase [15,19]. The grid system of the solid phase is separated from the one of the gas phase. With this additional separate grid, it is possible and convenient to apply the necessary very fine spatial resolution for the solid phase heat transfer (and the pyrolysis if the solid phase material is combustible). A very fine spatial resolution (about $1.0 \mathrm{~mm}$ ) along the perpendicular direction to the wall surface is applied, in order to capture the important thermal wave penetration. The grid resolution of the solid phase was 64,900 cells in the coarse-grid case and 138,600 cells in the fine-grid case.

Finally, all sets of simulation were validated against experimental tests described above, and each modeling scenario was calculated on a desktop computer with $2.40 \mathrm{GHz}$ Core $^{(\mathrm{TM})} 26600$ processor and 3GB of RAM.

\section{RESULTS AND DISCUSSIONS}

\section{Experimental Results}

Fire in the corridor as one kind of confined space can also be divided into several potential stages: ignition and early growth, smoke filling, fully developed or post-flashover, and decay. Typical fire growth stages of the experiments are shown in Fig. 4. Generally, it was observed that after a dozen seconds from ignition, the fire plume impinged on the ceiling and smoke moved along the corridor to the opening. A thin and stratified hot smoke layer can be seen to flow under the ceiling. Because of the air entrainment from the cold lower layer, the smoke layer became slightly thicker near the opening. Subsequently, the smoke temperature rose gradually, accompanied with the increase of the hot layer depth, which then fed back to the fire source and further enhanced the HRR of the fire source. This positive circulating mechanism continuously acted on the corridor fire until the unburnt gases accumulated in the smoke layer were sufficiently heated and begun to burn. By then, a rapid jump of temperature, $\mathrm{CO}$ concentration and radiation would take place.

Fig. 5a shows the typical temperatures recorded at different distances away from the fire, taking Test 1.a as an example. It is observed that smoke temperature reduced significantly along the corridor, from the fire source to the opening. Both the transient and maximum temperature near the fire source were much higher than those closer to the opening. One primary reason is via the thermal energy largely lost to the floor through thermal radiation as well as partly to the ceiling surface through convection. 
The typical gas concentration curves from Test 1.a are illustrated in Fig. 5b. It is found that the changes of $\mathrm{CO}_{2}$ and $\mathrm{O}_{2}$ concentration were concurrent, and with opposite trends. The concentration of $\mathrm{CO}$ grew subsequently with that of $\mathrm{CO}_{2}$, especially before the fully developed stage. A possible explanation is that during the growth and smoke filling period the fire was controlled by fuel supply, and combustion was sufficient; while in the fully developed stage, the fire was controlled by ventilation, and combustion of fuel became insufficient, resulting in the high concentration of $\mathrm{CO}$.

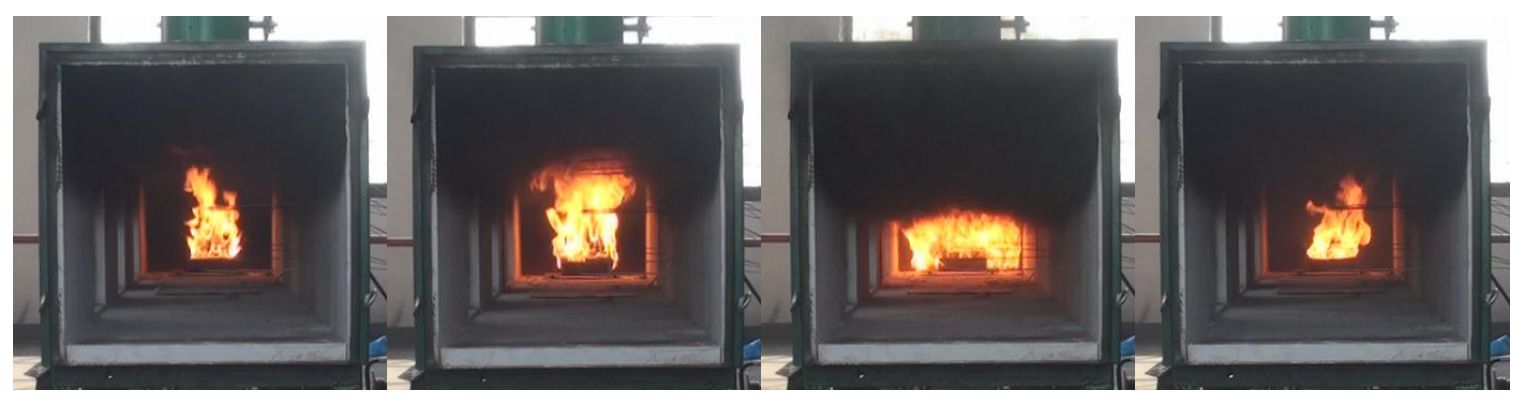

Fig. 4. The whole fire growth process in the corridor.

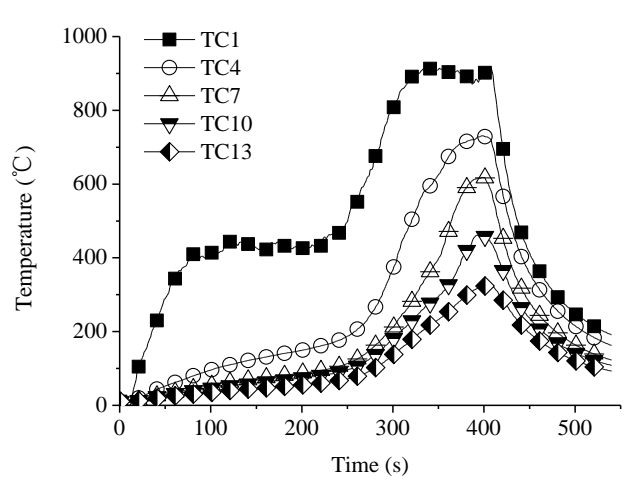

(a)

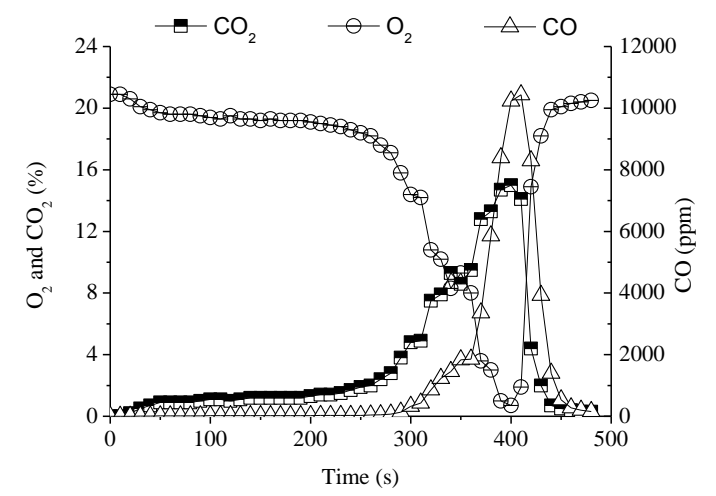

(b)

Fig. 5. The measured data curves in Test 1.a (TC referring to thermocouple): (a) temperature in the smoke layer; (b) gas concentration in the smoke layer of section B.

\section{Effect of Grid Resolution in Simulation}

In a CFD simulation, it is always important to first examine the effect of grid resolution and achieve the essentially grid-independent solution. As mentioned earlier, in this study, simulations were made using two different grid resolutions. In Fig. 6, temperature and $\mathrm{CO}_{2}$ predictions with two different grid resolutions are compared. As one can see, the fine grid simulation gives higher temperature and $\mathrm{CO}_{2}$ concentration. However, in general, the difference between two simulations can be regarded as acceptable for taking the fine grid resolution as sufficient. In principle, it would be desirable to further refine the grid resolution. But the further grid refinement will make the computation beyond the capacity of the currently available computer resource. 


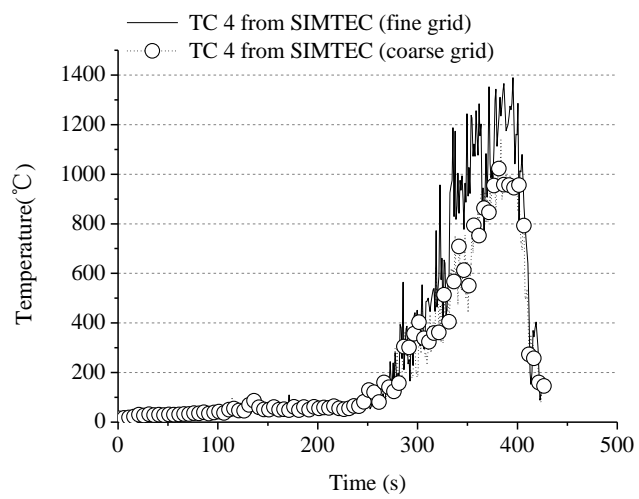

(a)

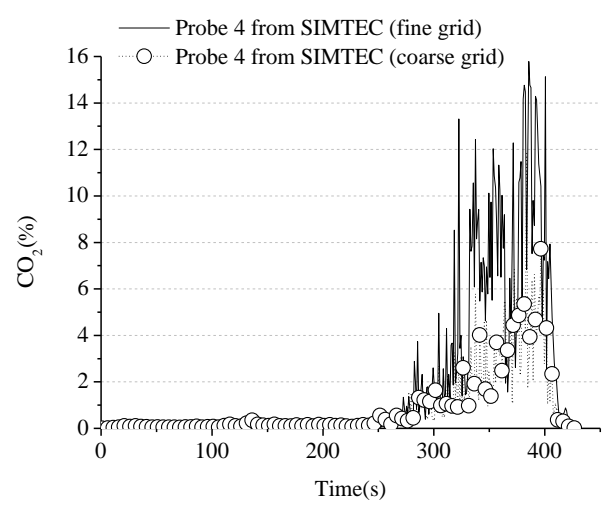

(c)

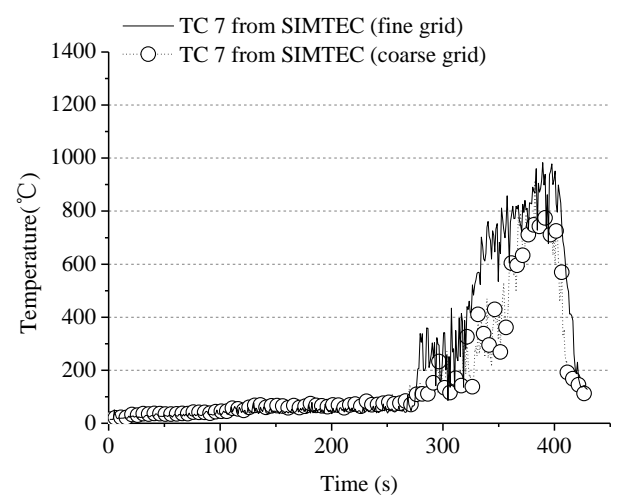

(b)

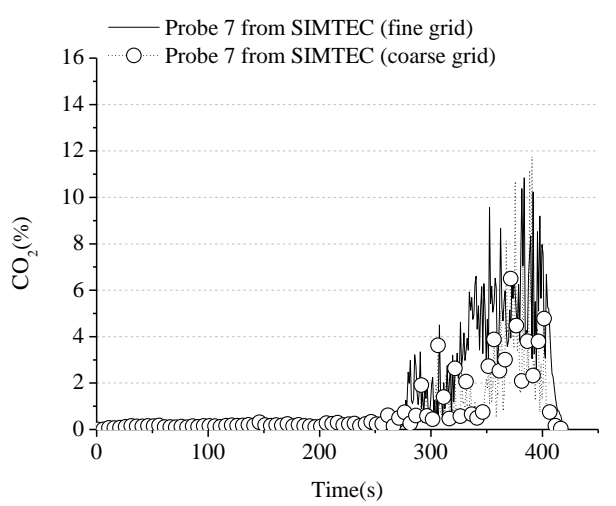

(d)

Fig. 6. Effect of different grids in the SIMTEC modeling. Thermocouple position: (a) Test 1.a at point 4; (b) Test 1.a at point 7; Gas probe position: (c) Test 1.a at point 4, (d) Test 1.b at point 7).

\section{General Observations of Simulated Results}

In this section, the simulated results corresponding to the condition of Test 1.a are presented. The typical temperature contour at the symmetrical longitudinal plane is shown in Fig. 7. Here it can be seen again that the hot layer remained thin during a relatively long period after the ignition and the depth was almost constant throughout the entire corridor. After nearly $5 \mathrm{~min}$, the smoke began to obviously accumulate under the ceiling, as a result of the enhanced HRR. When the HRR of the fire rose to the peak value, the fully developed fire stage took place. The temperature went up to $1200{ }^{\circ} \mathrm{C}$ near the impingement point, almost above $600{ }^{\circ} \mathrm{C}$ at the half-way point of the corridor and above $300{ }^{\circ} \mathrm{C}$ near the opening. Even though the hot layer temperature has dropped by about $900{ }^{\circ} \mathrm{C}$ at the end of the corridor, the depth still did not change obviously along the corridor. It can be concluded that there is not obvious air entrainment in the downstream smoke layer.

The velocity vectors of Test 1.a as shown in Fig. 8 depict the smoke movement and air entrainment on central plane during the fully developed stage. The fire plume moved upwards from the source, and after impinging on the ceiling it was confined to spread in one direction. The fresh air was entrained from the opening towards the fire source, which lies beneath the hot smoke layer. A neutral flow plane can be easily observed from the vector picture. Since a large pressure gradient existed at the upstream end of the ceiling flow, the velocity continuously increased until it reached the maximum value at the middle. Next, it began to decrease gradually due to the effects of viscosity. 

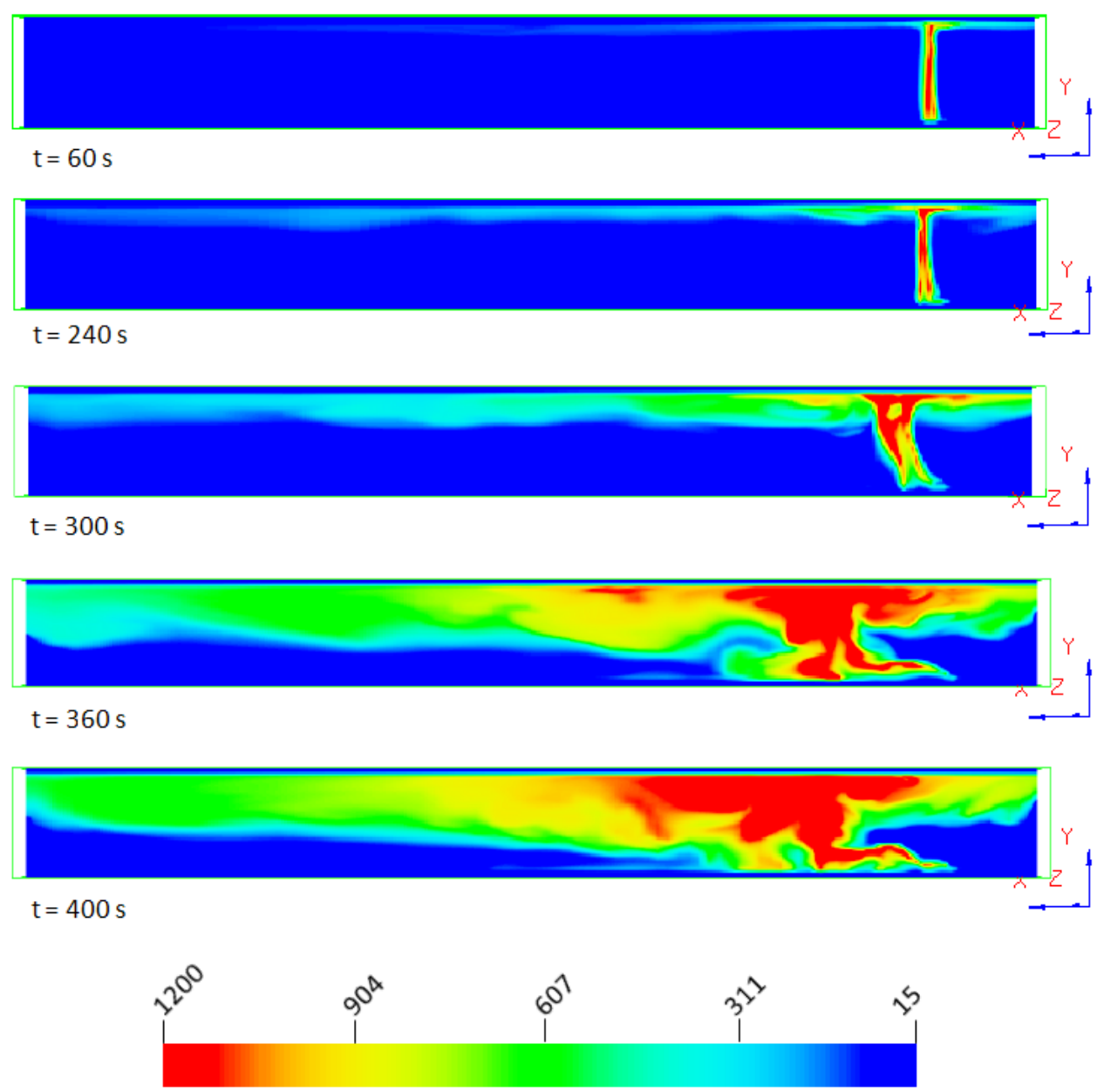

Temperature

${ }^{\circ} \mathrm{C}$

Fig. 7. Temperature contours of Test 1.a on central plane at different stages.

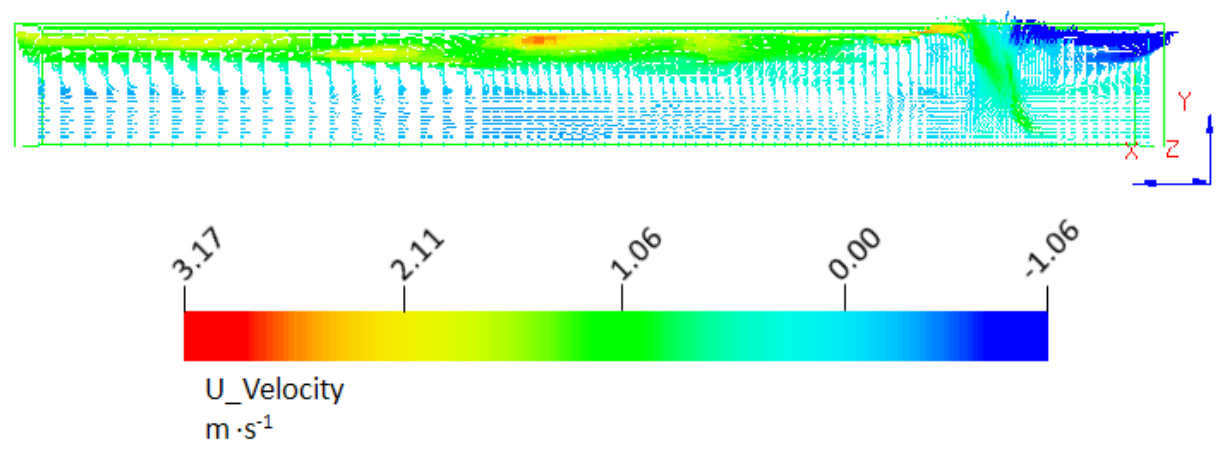

Fig. 8. Velocity vectors of Test 1 .a on central plane at time $300 \mathrm{~s}$.

\section{Comparison of Modeling and Experimental Results}

The predictions of smoke temperatures from SIMTEC have been compared with the experimental data at thermocouple 4, 7, 10, 13 of Test 1.a as shown in Fig. 9, respectively. The simulated results with coarse and fine grid are both plotted in the figure. Generally, there is a good agreement in predicting temperature growth of the fire-induced ceiling flow in the corridor. At the position of thermocouple 4 (Fig. 9a), which is 
the nearest one to the fire source, the measurement gave a higher temperature than the prediction at the fire growth stage. A possible reason is that intense radiation near the fire source caused the deviation of thermocouple measurement, where the actual local gas temperature was not so high. In the full-developed fire period, the simulation presents an over-prediction, particularly at the location nearest the fire source. At the last two downstream points (Fig. 9c and 9d), the prediction is reasonably close to the experimental data. The discrepancy can be due to uncertainties in both experimental measurement and numerical simulation. At the fully developed stage, the thermocouple is hot and radiates away heat. Therefore, the measured temperature can be lower than the local gas temperature. In the simulation, primary reasons for the higher temperature can be under-prediction of mixing between hot and cold gas, over-prediction of combustion rate at the under-ventilation condition by the turbulent combustion model and under-estimation of heat loss. The gas concentration comparison presented in the next section however reveals that the under-ventilation combustion rate seems to be reasonably captured by the modified EDC model. It also largely excludes the under-prediction of mixing between hot and cold gas. Therefore, the over-prediction of temperature could be largely due to under-prediction of heat loss. In the experiment, it was observed that a large amount of soot was produced. For such a fire, thermal radiation is dominant. In the simulation, as described by the chemical reactions discussed previously, the soot production factor was empirically chosen to be $5 \%$. For the confined fire, this soot production factor can be insufficient. As a result, the soot production can be under-estimated and thermal radiation heat loss can be under-predicted. It is also noted that in the LES computation, the thermal radiation was computed based on the filtered temperature and gas composition profiles, without consideration of the fluctuations in the fully transient variation. However, thermal radiation is a strongly non-linear function of temperature and gas composition profiles. This may also lead to an under-estimation of thermal radiation heat loss. Unfortunately, the thermal radiation heat loss was not measured in the experiment and the predicted radiation heat loss thus cannot be assessed.

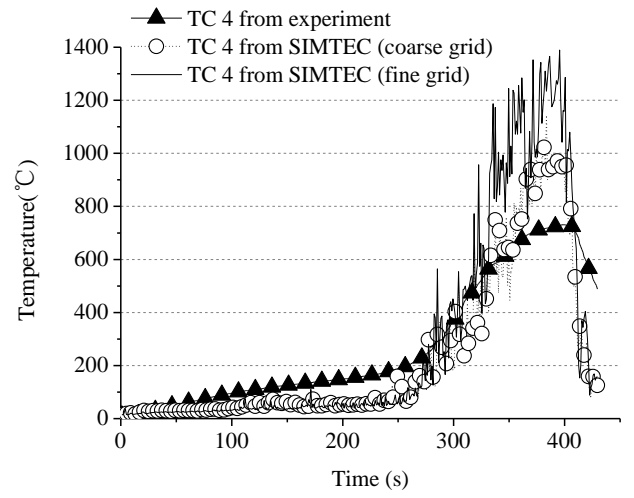

(a)

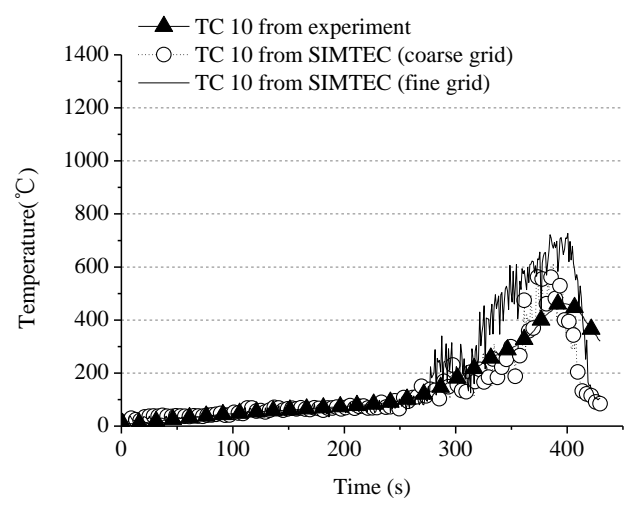

(c)

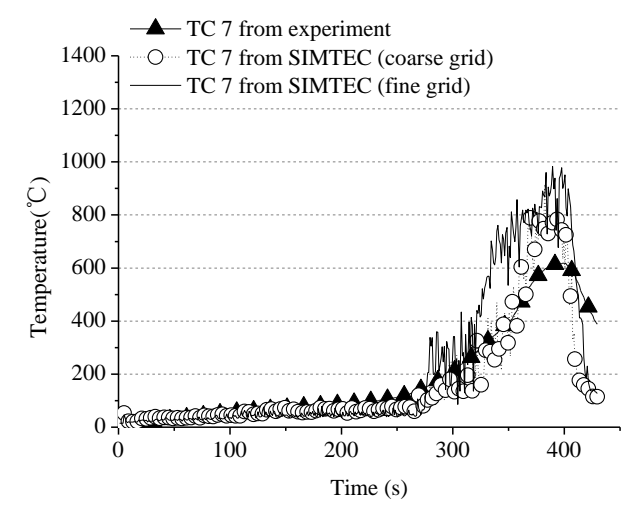

(b)

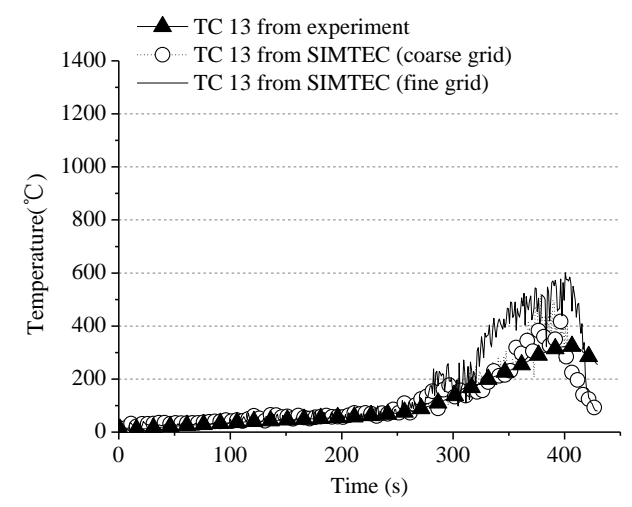

(d)

Fig. 9. Comparison of temperature-time plot between simulation and experimental data: (a) TC 4; (b) TC 7; (d) TC 10; (d) TC 13. 
As explained in the previous section, the gas concentration along the corridor was also measured in the tests. In Fig. 10, the predictions of $\mathrm{CO}_{2}$ concentration growth are compared with the experimental data. In general, the agreement is reasonably good. From the comparison, one may notice that the prediction gives lower values than the measurement. The chemical species $\mathrm{CO}_{2}$ is produced as the one of products from the chemical reaction. Once it is produced, it is then distributed but not consumed. This comparison therefore may indicate that the combustion intensity and turbulent mixing between combustion products and fresh air are not over-predicted in the simulation. With this, one may believe that the previously discussed overprediction of temperature is largely due to under-estimation of heat loss.

For an under-ventilated fire, $\mathrm{CO}$ concentration is of critical concern. However, the under-ventilation condition imposes a big challenge for turbulent combustion modeling, particularly when the modeling lacks consideration of chemical kinetics. In Fig. 11, the predictions of $\mathrm{CO}$ concentration growth are compared with the experimental data. The comparison shows that the $\mathrm{CO}$ concentration at the point close to the fire source is reasonably well captured, but the $\mathrm{CO}$ concentration at the point further away from the fire source is poorly predicted. At the far distance point, the measurement presents a high $\mathrm{CO}$ concentration. However, in the prediction, the $\mathrm{CO}$ concentration goes to a very low value. This indicates that the used modified EDC turbulent combustion model must still be subject to further improvement in order to give a better prediction of $\mathrm{CO}$ distribution in an under-ventilated fire. For an under-ventilated turbulent combustion, the ultimate solution for a proper modeling is to include the consideration of chemical kinetics. As mentioned earlier, a new turbulent combustion model with consideration of chemical kinetics has now been developed and implemented in SIMTEC. This model is to be used for a further study in the near future.

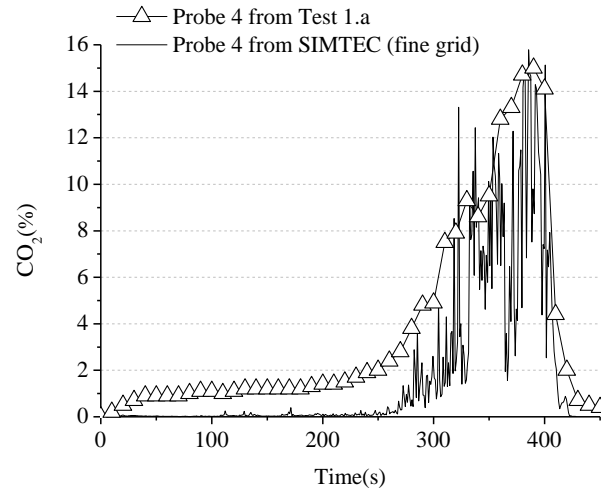

(a)

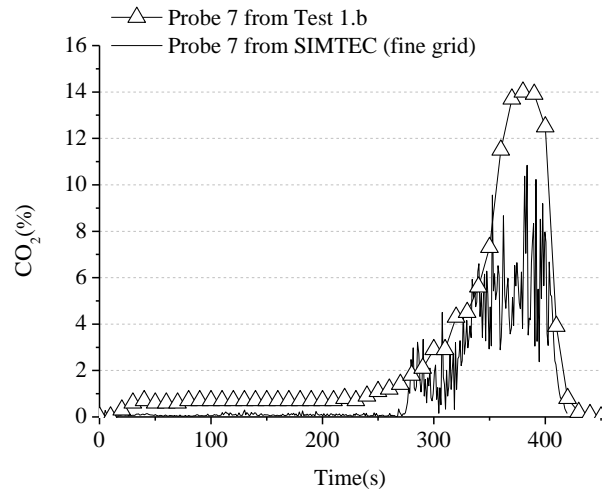

(b)

Fig. 10. Comparison of $\mathrm{CO}_{2}$ concentration-time plot at different distance from fire. Gas probe position: (a) Test $1 . \mathrm{a}$ at point 4 ; (b) Test $1 . \mathrm{b}$ at point 7.

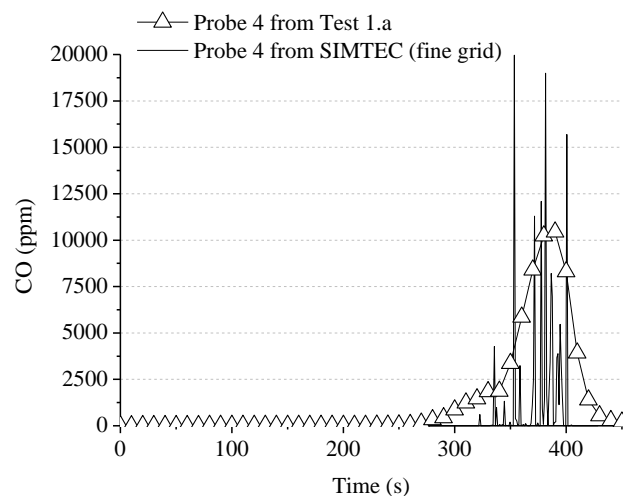

(a)

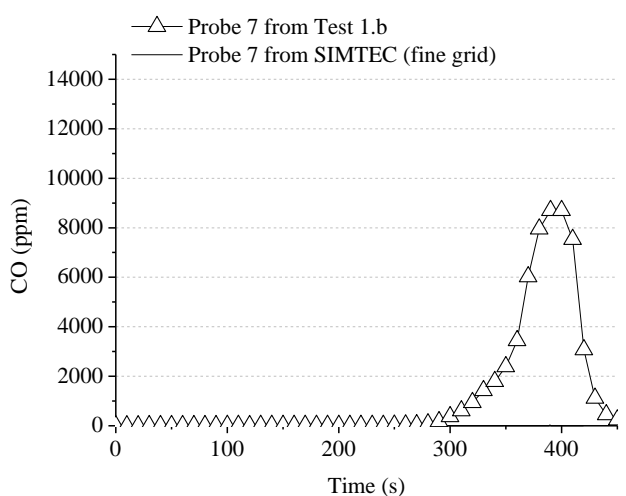

(b)

Fig. 11. Comparison of $\mathrm{CO}$ concentration-time plot at different distance from fire. Gas probe position: (a)

Test 1.a at point 4; (b) Test 1.b at point 7. 


\section{Effect of Increasing Fire Source Size}

In this study, effect of increasing the fire source size was also investigated, both experimentally and numerically. By varying the dimension of the pool fire from $15 \times 15$ to $17 \times 17$ and $20 \times 20 \mathrm{~cm}$, and keeping all other parameters fixed (denoted as Test 3, 1.a and 2, respectively), we increased the heat release rate from the fire source. The averaged hot layer temperature at the post-flashover stage, as a function of the distance along the corridor, is illustrated in Fig. 12.

From the measured values (scatter), a temperature decrease from the fire source to the opening is revealed in all tests. The temperature difference among the three tests is not discernible near the fire source, whereas at the end of the corridor the difference becomes distinct. The simulated data (scatter lines) indicate that in all three tests the hot smoke temperature dropped sharply along the corridor and the maximum values took place about $30 \mathrm{~cm}$ away from fire source. Similarly, the temperature discrepancy at the end of the corridor is larger than that near the fire source, especially for Tests 2 and 1.a. The agreement between the numerical and experimental results is good, especially at the position of $0.5 \mathrm{~m}$ (point 1 in Fig. 1a), which is just above the fire source. However, substantial over-predictions exist at the position of $1.5 \mathrm{~m}$ (point 4 in Fig. 1a).

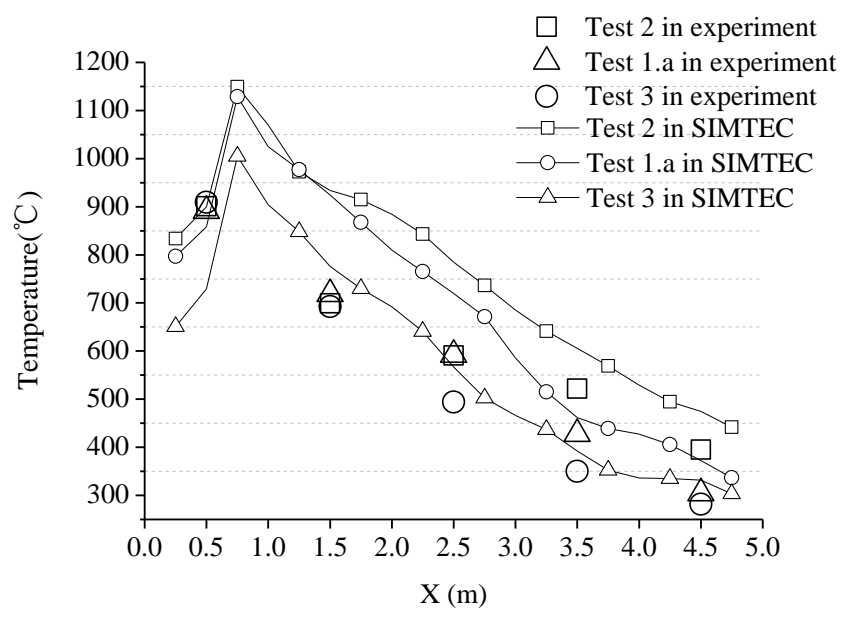

Fig. 12. Average hot layer temperature during fully developed stage.

\section{CONCLUSIONS}

A series of fire experiments and corresponding CFD simulations were performed to study the fire in a confined reduced-scale corridor. The simulation was validated against experimental measurements. The results, including ceiling jet flow temperature, concentration of $\mathrm{CO}$ and $\mathrm{CO}_{2}$, are compared and analyzed.

In both the experiment and the modeling, in general, obvious stratification was observed after the fire plume impinged upon the ceiling. The corridor fire experienced a quasi-steady state until the hot layer began to burn, thereafter the temperature, $\mathrm{CO}$ and $\mathrm{CO}_{2}$ concentration rose sharply. At each specific time, the temperature, $\mathrm{CO}$ and $\mathrm{CO}_{2}$ concentration in the ceiling flow decayed gradually along the corridor. The CFD code SIMTEC predicts the hot layer temperature and $\mathrm{CO}_{2}$ concentration with good accuracy, especially at the position closer to the end of the corridor. The $\mathrm{CO}$ concentration close to the fire source is also well captured in the simulation. However, the $\mathrm{CO}$ concentration prediction at the downstream location further away from fire source is poor. Further research is needed to improve the modeling of turbulent combustion at the under-ventilated condition, in particular to better consider the interaction between chemical kinetics and turbulence.

The effect of corridor fire intensity on characteristics of temperature and gas concentration profile of ceiling jet flow are also investigated and discussed. Both experiment and numerical simulations indicate that the average hot layer temperature near fire source did not vary significantly with increase of the fire source size. 
It is revealed in this study that the hot layer burning phenomenon can impose a severe hazard for underground fire safety. Measures should be taken to avoid such hazards in a fire safety design of relevant underground space. The validation performed in this work gives support on the applicability and suitability of SIMTEC to fire safety design for underground spaces.

\section{ACKNOWLEDGEMENTS}

The experimental work in this study was financially supported by the National Natural Science Foundation of China under Grant No. 50974110 and Grant No.51028401. One of the authors, Songyang Li also would like to give special thanks to the Department of Energy Sciences, Lund University, for hosting him as a visiting $\mathrm{PhD}$ student.

\section{REFERENCES}

[1] Xue, H., Chew, T.C., Tay, K.L. and Cheng, Y.M., (2000) Control of ventilation airflow for tunnel fire safety, Combustion Science and Technology 152: 179-196, http://dx.doi.org/10.1080/00102200008952133

[2] Studiengesellschaft Strahlenwendung e.V., "Fires in Transport Tunnels, Report of Full Scale Tests," EUREKA-Project EU 499: FIRETUN, D-40213, Düsseldorf, Germany, 1995.

[3] Ingason, H. and Lönnermark, A., (2005) Heat release rates from heavy goods vehicle trailer fires in tunnels, Fire Safety Journal 40: 646-668, http://dx.doi.org/10.1016/j.firesaf.2005.06.002

[4] Lönnermark, A. and Ingason, H., (2005) Gas temperatures in heavy goods vehicle fires in tunnels, Fire Safety Journal 40: 506-527, http://dx.doi.org/10.1016/j.firesaf.2005.05.003

[5] Nilsen, A.R. and Log, T., (2009) Results from three models compared to full-scale tunnel fires tests, Fire Safety Journal 44: 33-49, http://dx.doi.org/10.1016/j.firesaf.2008.03.001

[6] Jones, W.W. and Forney, G.P., "A programmer's reference manual for CFAST, the unified model of fire growth and smoke transport", National Institute of Standards and Technology Report, NISTTN 1283, Gaithersburg, MD, 1990, 100 p.

[7] Charters, D.A., Gray, W.A. and McIntosh, A.C., (1994) A computer model to assess fire hazards in tunnels (FASIT), Fire Technology 30: 134-154, http://dx.doi.org/10.1007/BF01040993

[8] McGrattan, K.B. and McDermott, R., "Fire Dynamics Simulator (Version 5) - User's Guide", National Institute of Standards and Technology, NIST Special Publication 1019-5, Gaithersburg, MD, 2010, 206 p.

[9] Jain, S., Kumar, S., Kumar, S. and Sharma, T.P., (2008) Numerical simulation of fire in a tunnel: Comparative study of CFAST and CFX predictions, Tunnelling and Underground Space Technology 23: 160-170, http://dx.doi.org/10.1016/j.tust.2007.04.004

[10] Cox, G. and Kumar, S., (1987) Field modeling of fire in forced ventilated enclosures, Combustion Science and Technology 52: 7-23, http://dx.doi.org/10.1080/00102208708952565

[11] Tuovinen, H., (1996) Validation of ceiling jet flows in a large corridor with vents using the CFD code JASMINE, Fire Technology 32: 25-49, http://dx.doi.org/10.1007/BF01040756

[12] Lee, S.R. and Ryou, H.S., (2006) A numerical study on smoke movement in longitudinal ventilation tunnel fires for different aspect ratio, Building and Environment 41: 719-725, http://dx.doi.org/10.1016/j.buildenv.2005.03.010

[13] Hu, L.H., Huo, R., Peng, W., Chow, W.K. and Yang R.X., (2006) On the maximum smoke temperature under the ceiling in tunnel fires, Tunnelling and Underground Space Technology 21: 650-655, http://dx.doi.org/10.1016/j.tust.2005.10.003

[14] Yan, Z.H., "SIMTEC User Manual” (also http://www.simtecsoft.com), Lund, Sweden, 2010.

[15] Yan Z.H., "CFD modeling of fires and its recent development," Transport Phenomena in Fires, Sunden B. and Faghri M. (ed.), WIT Press, ISBN 978-1-84564-160-3, 2008. 
[16] Magnussen, B.F. and Hjertager, B.H., "On mathematical modeling of turbulent combustion with special emphasis on soot formation and combustion", $16^{\text {th }}$ Symposium (International) on Combustion, Combustion Institute, Pittsburg, Pennsylvania, 1976, pp.719-729.

[17] Hoffmann, K. and Chiang S.T., Computational Fluid Dynamics Vol.III, Engineering Education System, Wichita, Kansas, 2000, p. 148.

[18] Modak, A.T., (1979) Radiation from products of combustion, Fire Safety Journal 1: 339-361, http://dx.doi.org/10.1016/0379-7112(79)90004-3

[19] Yan Z.H., (2002) Parallel computation of turbulent combustion and flame spread in fires, Numerical Heat Transfer, Part B: Fundamentals 41: 191-208,

http://dx.doi.org/10.1080/104077902317240076 